\title{
ANALYSIS AND ASSESSMENT OF DYNAMIC RESPONSE TO PASSENGERS DURING LIFT EMERGENCY BRAKING
}

\author{
Tomasz Magiera' ${ }^{1}$ Paweł Kułaga' ${ }^{1}$, Kaja Wójcik
}

1 AGH University of Science and Technology, Faculty of Mechanical Engineering and Robotics, Department of Rope Transport, Kraków, Poland, e-mail: magiera@agh.edu.pl, pkulaga@agh.edu.pl, skrzypie@student.agh.edu.pl

Received: 2017.05.15

Accepted: 2017.08.01

Published: 2017.09.03

\begin{abstract}
The paper presents an analysis and assessment of recorded accelerations acting on Hybrid III dummy during emergency braking of a passenger lift. The dummy was equipped with a system of three-axis accelerometers. The type of progressive safety gear that has the shortest time of reaction and the shortest effective braking distance in its group, was chosen for tests. The tests were carried out on an emplacement, which simulated the movement of passenger lift. Tests of emergency braking were performed at variable load of a cabin corresponding to the mass of different passengers number. The cabin was dispelled by the gravity force using its free-fall. During the braking, the values of accelerations effected on individual parts of dummy, were measured. Based on them and using HIC and Nij indexes, the impact of temporary accelerations on passenger's health was determined.
\end{abstract}

Keywords: emergency braking, passenger lift, dummy, progressive safety gears, HIC index

\section{INTRODUCTION}

Passenger lifts as a type of conveyor system, must provide the required level of passenger safety and comfort, which are specified in the European Union Directive [1] and in a ISO standard [7]. In order to guarantee of relevant standards, the safety gears, speed restrictors and PTC thermistor switchoff devices are used [13]. The occurrence of a dangerous situation and the activation of at least one of the safety systems may affect the comfort level of passengers of the passenger lift, but should not damage their health. There is a probability of an adverse impact on passenger health and comfort, as a result of temporary acceleration caused by safety gear working effect. This condition may occur despite the required condition of the permissible delay value of the whole braking process [1]. For that reason there is a need to perform the test of the influence of dynamic effect on passengers during emergency braking of passenger lift cabin using safety gears.

\section{STATE OF THE ART}

The dynamic issues of lifts and their influences, both on technical elements and passengers, were conducted inter alia by authors in the articles [6] and [24]. Herra and others in [6] presented the standardised way of determination stiffness and dumping coefficients of a platform lift. Moreover, Vladic and others [24] showed a dynamic model of a lift, which calculates a critical lifting speed value. On reaching this value, a rope slippage may be a trigger to free-fall of the lift and as a result of it, activates safety gears.

The passengers ride comfort and methods improving it, were presented in [25]. In which, Yang and others showed the model based on fuzzy logic approach, which controlled a unit of passengers lifts. Furthermore, Lonkwic and Gardynski in [9] put across a possible way of reducing oscillations, which are transmitted on a cabin from drive elements. Additionally, Herra and Kaczmarczyk in 
[5] determined a dumping coefficient, according to a type of passengers shoes.

The research, concerned a dynamic influence on lift passengers during a failed emergency braking process, were conducted by Funai and others and presented in [3]. Authors analysed and evaluated hits of a fully loaded cabin with a dummy or a volunteer inside, directly into set down buffers. As a result of it, the mathematical model for predicting dynamic influences on passengers, for that kind of emergency situations, was developed. The design subject matters of safety gears and their effects on passenger safety were discussed in $[8,10,11,12]$. Lonkwic in [8] presented results from tests of different types of progressive safety gears, according to variable load and measured stopping distance of a cabin. The results showed that a type CHP-2000 of a progressive safety gear, presented in [10] and [11], is characterised by the shortest effective stopping distance and the shortest time of acting.

In theory, considering a shorter stopping distance and retain an acceptable mean value of deceleration of a cabin, a higher level of passengers safety is provided. However, the shorter stopping distance brings on higher dynamic impact on passengers, which may results in negative influence on a bone system, especially a spine and internal organs [21].

The Severity Index (SI) is a general criterion to asses influences from short time accelerations on humans health. To analyse sudden processes of changing accelerations, the Crash Severity Index is used. However, in [18] was showed that CSI may not be efficient enough in assessment of probability of injury and it depends on a large number of factors, which their influences on CSI value are not unambiguously set out.

The analysis of a process of changing speed values is defined by variables such as: its duration, a value and a course action of force towards human body. The authors in [23] showed that each of them significantly effect on human health. This process is assessed by Human Linear Tolerance (HLT), for which maximal acceptable value for a human is indicated on $35 \mathrm{~g}$. Under the assumptions that the force acts in a frontal plane direction and time duration is less than $30 \mathrm{~ms}$. The worst-case of a dynamic influence on human occurs in vertical direction consistent with the gravity force. The human limit for this case is stated on $12 \mathrm{~g}$ in $30 \mathrm{~ms}$ time duration. However, decreasing the analysed duration time to $10 \mathrm{~ms}$, the value of threshold of human endurance increases to values: $45 \mathrm{~g}$ for frontal impact and $25 \mathrm{~g}$ for vertical force direction [2, 16]. Analysis and assessment of dynamic influences on particularly exposure human body parts, such as head and neck spine section, are defined by two indexes: Head Injury Criterion (HIC) (1) and Neck Injury Criterion (Nij) (2) presented in $[2,4,14,19,20]$.

$$
H I C=\max \left[\left(\frac{1}{t_{2}-t_{1}}\right) \cdot \int_{t_{1}}^{t_{2}} \bar{a} \cdot d t\right]^{2,5} \cdot\left(t_{2}-t_{1}\right)
$$

where: $\left(t_{1}, t_{2}[s]-\right.$ duration of a maximal acceleration, $\bar{a}\left[\mathrm{~m} / \mathrm{s}^{2}\right]-$ a mean value of acceleration in analysed time period,

$$
N i j=\frac{F_{x}}{F_{x_{\text {crit }}}}+\frac{M_{x}}{M_{x_{\text {crit }}}}
$$

where: $F_{x}[N]$ i $M_{x}[N m]$ - shearing force and bending moment act in a neck spine section, $\mathrm{F}_{\text {xcrit }}[\mathrm{N}] \mathrm{i} \mathrm{M}_{\text {xcrit }}[\mathrm{Nm}]$ - critical values of shearing force and bending moment.

The generally accepted time periods use for analysis of temporary dynamic influences on human body are $10 \mathrm{~ms}$ and $15 \mathrm{~ms}$. The threshold, above which a serious brain damage may occur, for $15 \mathrm{~ms}$ period is determined to 700 [2] and for $10 \mathrm{~ms}$ to 1000 [19]. Index Nij has no unambiguously defined the threshold, however the authors in [21, 22, $26]$, presented that the value of $40 \mathrm{~g}$ in $10 \mathrm{~ms}$ time duration may occur significant damages of spine, and the value of the index, in this case, equals 1 .

\section{SELECTION OF THE EQUIPMENT AND METHODOLOGY OF CARRYING EMERGENCY BRAKING TESTS}

A progressive safety gear (type CHP 2000) was chosen for the tests to determine the actual dynamic impacts on the most expose parts of the passenger's (dummy) body during the emergency braking of the lift cabin. The criteria of choosing the safety gear to the tests were: the shortest effective braking distance and the shortest time of delay. The choice of the experiment safety gear was based on the test results of the various types of safety gears carried out for the variable load parameters of the cabin and the different heights of its free-fall $[10,11]$.

The safety gear CHP 2000 is characterised by the progressive changes of braking force. During normal operation of the lift, a safety gear 


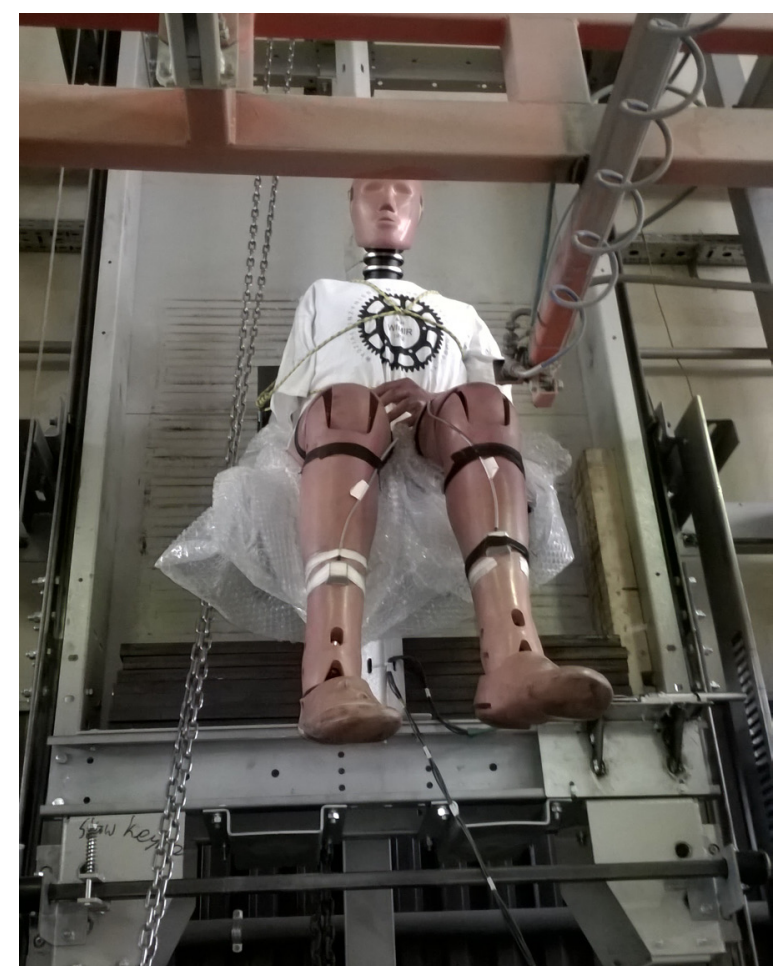

Fig. 1. The test dummy Hybrid III placed on the measuring site

is triggered by a speed restrictor after exceeding $115 \%$ of the nominal speed of the cabin. The maximum force of a roller clamp to the cabin drive is set by the pre-deflection of the spring discs. The maximum braking force is reached at the end of the process, when the roll reaches the maximum permissible displacement in the safety gear case.

In order to perform the tests, the described site in $[8,10]$ was properly modificated (Figure 1 and Figure 12).

The test dummy Hybrid III, equipped with six three-axis accelerometers in the range of $+/$ $20 \mathrm{~g}$ and a registration frequency of $1000 \mathrm{~Hz}$, was used for the tests. Accelerometers were placed in the head, in the chest (at the base of the cervical segment) and on each of the limb of the dummy. Registration system was placed inside the dummy and was launching before every test.

The speed of loaded cabin in a free-fall was measured by an optical sensor. The accuracy of the measurement was defined by $10 \mathrm{~mm}$ optical markers. The measurement frequency of the optical sensor was $100 \mathrm{~Hz}$. The dummy was placed on the platform, which was directly connected to cabin drives. As a result of it, the maximum force acted along the spine axis.
All tests of emergency braking of passenger lift cabin were characterised by the same height of cabin free-fall $(125 \mathrm{~mm})$ after which the progressive safety gears were released. The value of the free-fall height was assorted to provide the speed of the cabin, in the moment of safety gears activation, equalled to a normal lift speed during operation.

The variable test parameter was the cabin load. The difference between the tests, corresponded to the nominal load of one passenger. The range of variable load with the mass of the cabin $(258,9 \mathrm{~kg}$ ) was presented in (Table 1). After every braking test, the braking distance and the technical condition of the clamping roller of the safety gear, the condition of cleanliness, geometric parameters and straightness of the cabin drive were evaluated. The clamping roller of the safety gear was replaced and the cabin drive was cleaned, if it did not comply with its nominal geometric parameters.

The emergency braking tests were carried out with the gradual increase of the load cabin, in order to reduce the probability of deformation of the cabin drives. Before every test the measuring system was switch on in a proper advance, in order to stabilise potential system vibrations.

\section{RESULTS}

Tests of cabin emergency braking were conducted with incremental cabin load. It resulted in a longer stopping distance and decreasing a mean value of deceleration of the whole braking process in every next test (Table 1). The highest values of deceleration (peaks) acting on the dummy were measured in the first test (a minimal loaded

Table 1. Established and measured parameters for emergency braking tests

\begin{tabular}{|c|c|c|c|c|}
\hline & $\begin{array}{c}\text { Distance } \\
\text { of a free } \\
\text { fall of the } \\
\text { cabin [mm] }\end{array}$ & $\begin{array}{c}\text { Stopping } \\
\text { distance } \\
\text { [mm] }\end{array}$ & $\begin{array}{c}\text { Cabin } \\
\text { load } \\
\text { [kg] }\end{array}$ & $\begin{array}{c}\text { Mean value of } \\
\text { deceleration } \\
\text { [g] }\end{array}$ \\
\hline $\begin{array}{c}\text { TEST } \\
1\end{array}$ & 125 & 210 & 337,3 & 0,62 \\
\hline $\begin{array}{c}\text { TEST } \\
2\end{array}$ & 125 & 215 & 415,7 & 0,61 \\
\hline $\begin{array}{c}\text { TEST } \\
3\end{array}$ & 125 & 220 & 494,1 & 0,59 \\
\hline $\begin{array}{c}\text { TEST } \\
4\end{array}$ & 125 & 235 & 572,5 & 0,56 \\
\hline $\begin{array}{c}\text { TEST } \\
5\end{array}$ & 125 & 255 & 650,9 & 0,52 \\
\hline
\end{tabular}


Table 2. Maximal measured acceleration values acting on different parts of dummy

\begin{tabular}{|c|c|c|c|c|c|c|}
\hline & $\begin{array}{c}\text { Head } \\
\text { [g] }\end{array}$ & $\begin{array}{c}\text { Chest } \\
\text { [g] }\end{array}$ & $\begin{array}{c}\text { Left } \\
\text { hand } \\
\text { [g] }\end{array}$ & $\begin{array}{c}\text { Right } \\
\text { hand } \\
\text { [g] }\end{array}$ & $\begin{array}{c}\text { Left } \\
\text { leg } \\
\text { [g] }\end{array}$ & $\begin{array}{c}\text { Right } \\
\text { leg } \\
\text { [g] }\end{array}$ \\
\hline $\begin{array}{c}\text { TEST } \\
\mathbf{1}\end{array}$ & 10,25 & 8,60 & 13,58 & 14,00 & 8,08 & 8,29 \\
\hline $\begin{array}{c}\text { TEST } \\
\mathbf{2}\end{array}$ & 10,04 & 8,95 & 13,32 & 13,40 & 8,13 & 8,60 \\
\hline $\begin{array}{c}\text { TEST } \\
3\end{array}$ & 8,16 & 6,87 & 9,05 & 9,93 & 6,49 & 6,78 \\
\hline $\begin{array}{c}\text { TEST } \\
4\end{array}$ & 6,73 & 6,16 & 6,53 & 6,61 & 6,52 & 6,87 \\
\hline TEST \\
5
\end{tabular}

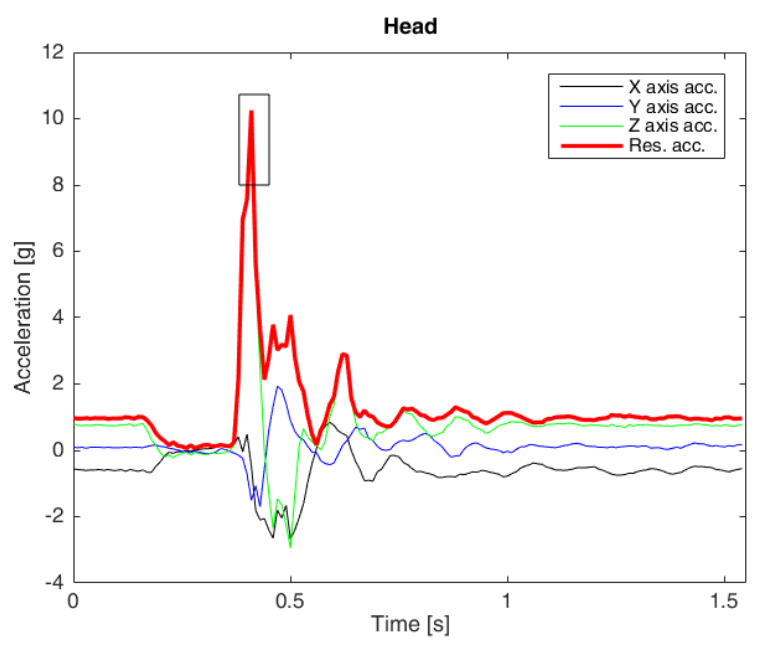

Fig. 2. Profile of registered acceleration values in the dummy head with the calculated resultant value TEST 1

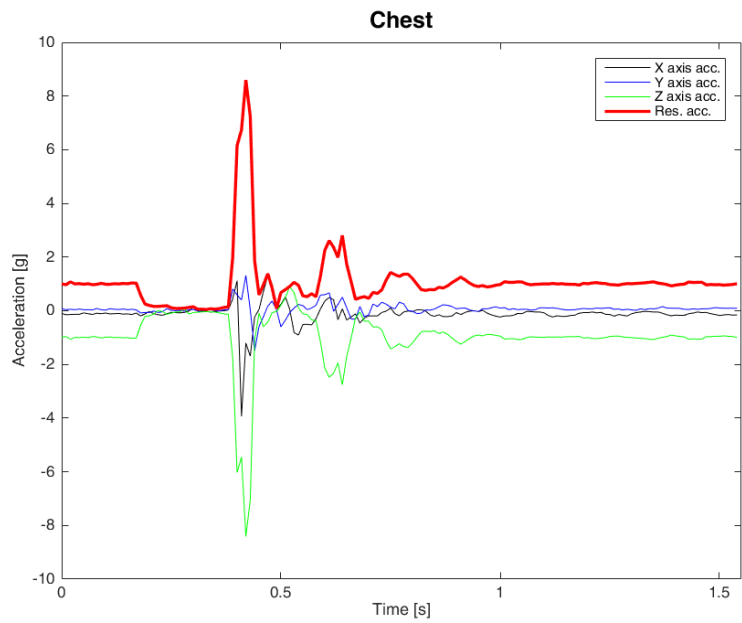

Fig. 3. Profile of registered acceleration values in the dummy chest/neck with the calculated resultant value - TEST 1

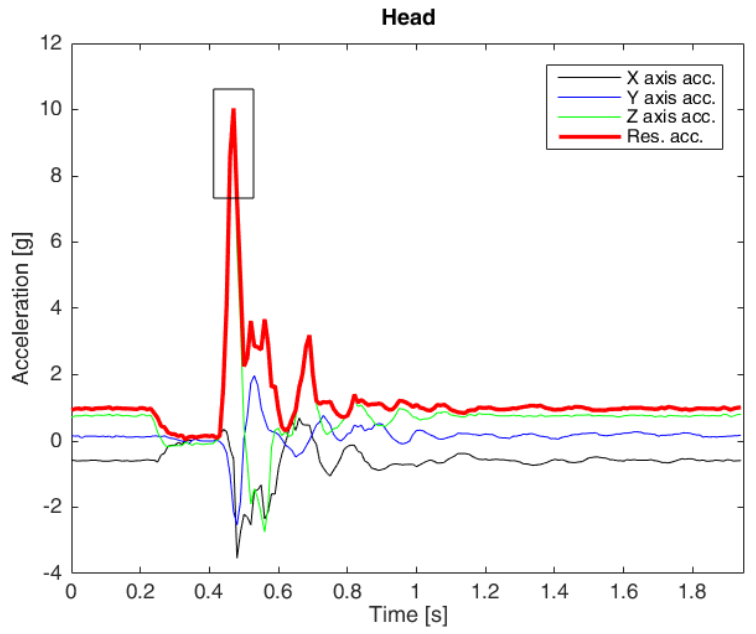

Fig. 4. Profile of registered acceleration values in the dummy head with the calculated resultant value -

TEST 2

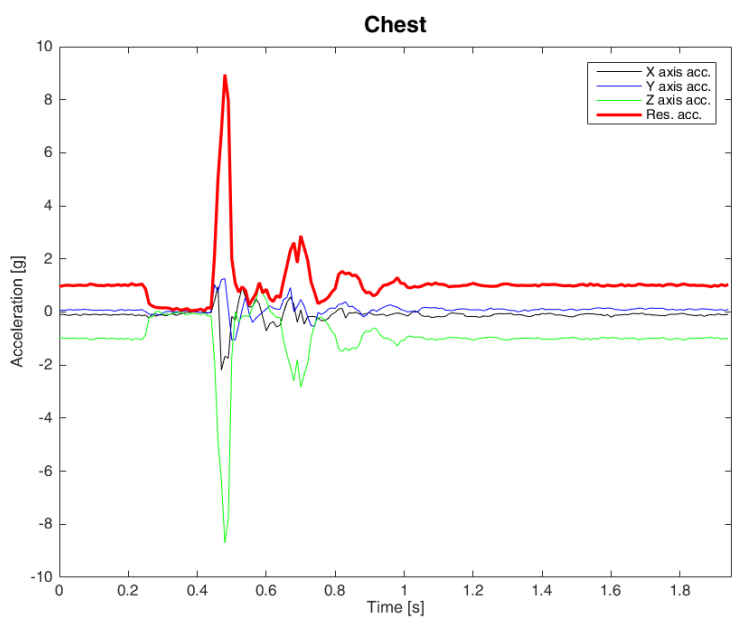

Fig. 5. Profile of registered acceleration values in the dummy chest/neck with the calculated resultant value - TEST 2

cabin) and the slightest were measured while the cabin was maximal loaded (Table 2).

The Table 1 . shows that mean values of deceleration of the whole braking process, according to concern standards, are acceptable. In spite of that registered values of acceleration acting on the dummy (Table 2), are more than 4-8 times over the ISO standard threshold of mean value for the whole braking process [7].

The preliminary analysis of maximal registered values of accelerations acting on dummy parts (Table 2) resulted in, that only measured values acting on the head and the neck (chest) were taken to further analysis. Despite that ac- 


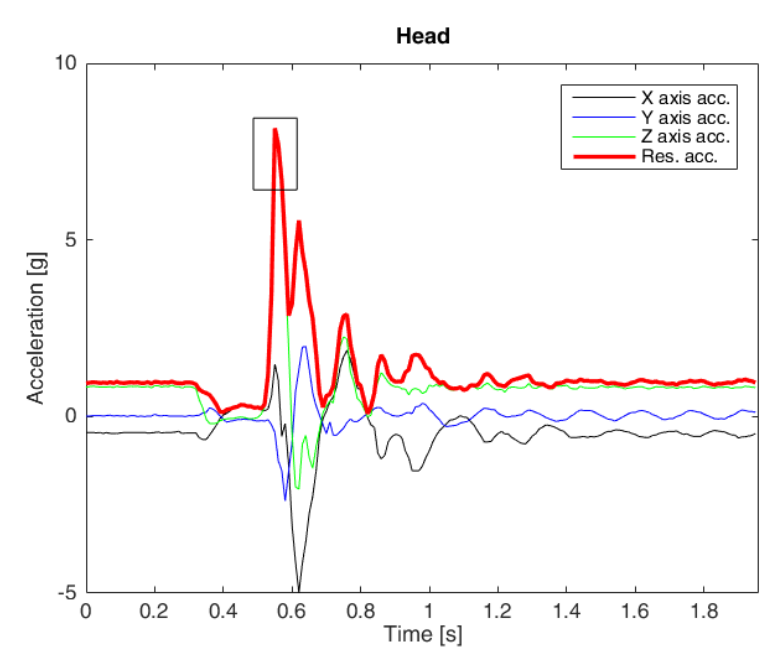

Fig. 6. Profile of registered acceleration values in the dummy head with the calculated resultant value -

TEST 3

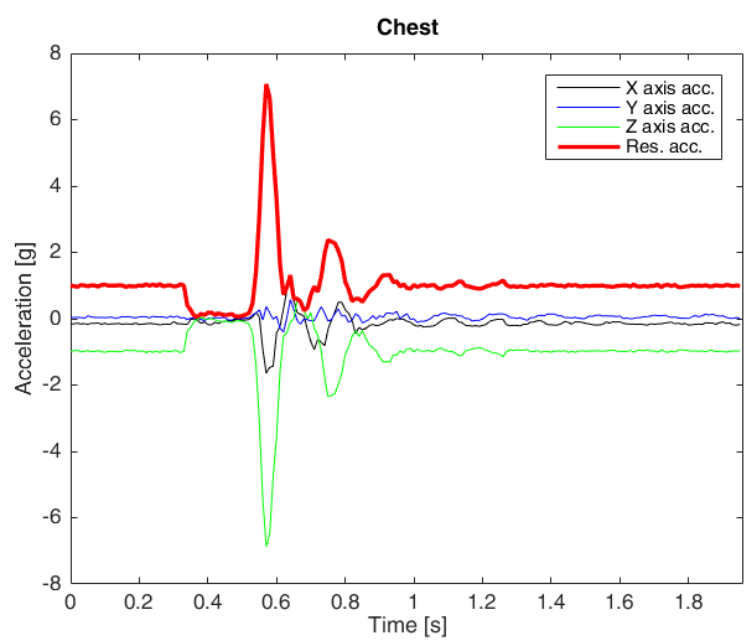

Fig. 7. Profile of registered acceleration values in the dummy chest/neck with the calculated resultant value - TEST 3

celerations values acting on hands and legs were the highest (hands: 5,01-14,00g, legs: 4,75$8,08 \mathrm{~g}$ ), based on HLT index, they were in the acceptable range [23].

Figures from 2 to 11 present the measured values (in three axes) of accelerations with calculated resultants values, acting on the head and the neck of the dummy. The black colour corresponds to $\mathrm{x}$-axis, blue to $\mathrm{y}$-axis, green to $\mathrm{z}$-axis values (Figure 12), while the red corresponds to resultant values from all three axes. To the calculations of values of HIC index were used values from specified time windows, showed in Figures 2, 4, 6, 8 and 10).

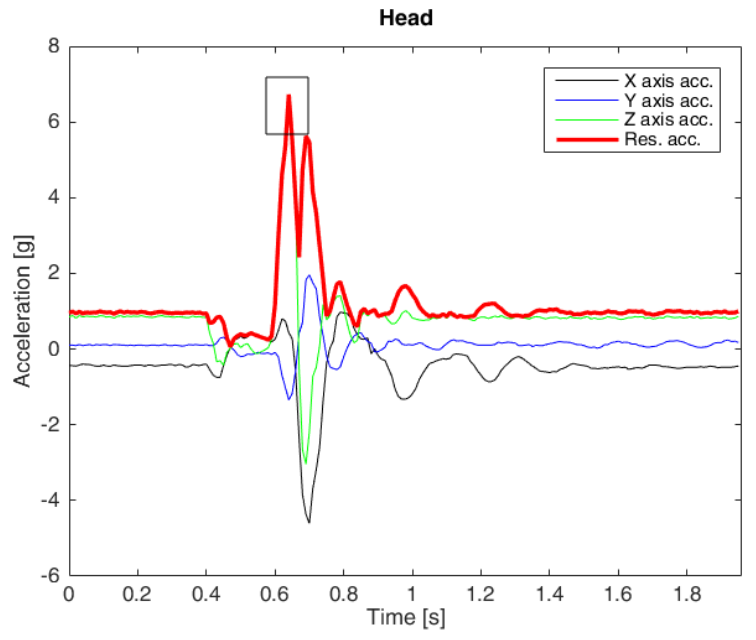

Fig. 8. Profile of registered acceleration values in the dummy head with the calculated resultant value -

TEST 4

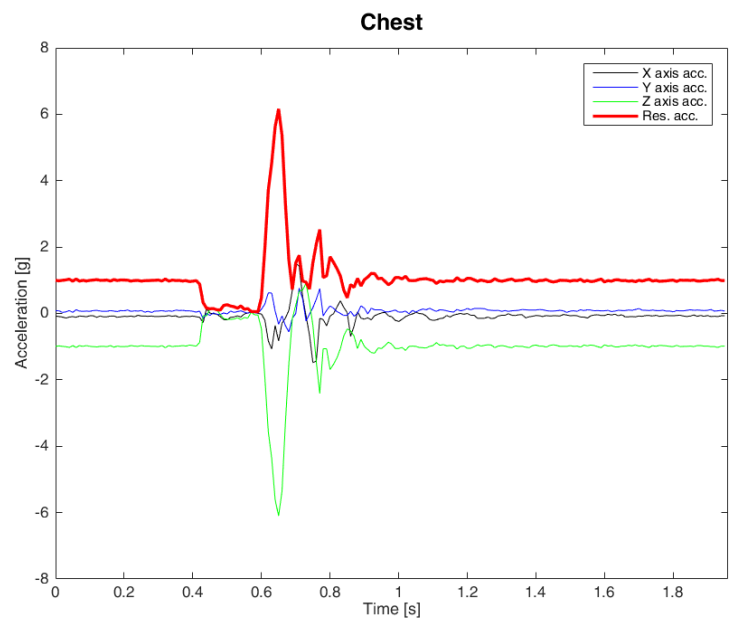

Fig. 9. Profile of registered acceleration values in the dummy chest/neck with the calculated resultant value - TEST 4

Figures 3, 5, 7, 9 and 11 present registered values by the chest accelerometer during emergency braking tests. To the calculations of values of Nij index were used maximal measured acceleration values.

Recorded accelerations by the accelerometers located in the dummy head (Figure 12), were acting in direction in line with the spine axis. The registered values were in the range between 4,73$10,25 \mathrm{~g}$. The highest $\mathrm{g}$-forces were registered during the braking process with loaded cabin only by the dummy. The $\mathrm{x}$-axis acceleration values registered by a chest accelerometer (Figure 12), were higher in the first two tests with limited load 


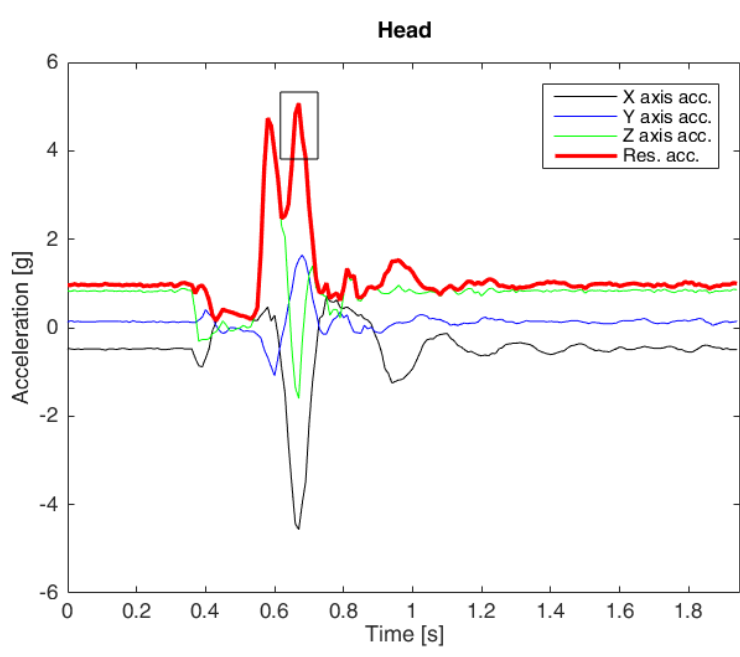

Fig. 10. Profile of registered acceleration values in the dummy head with the calculated resultant value TEST 5

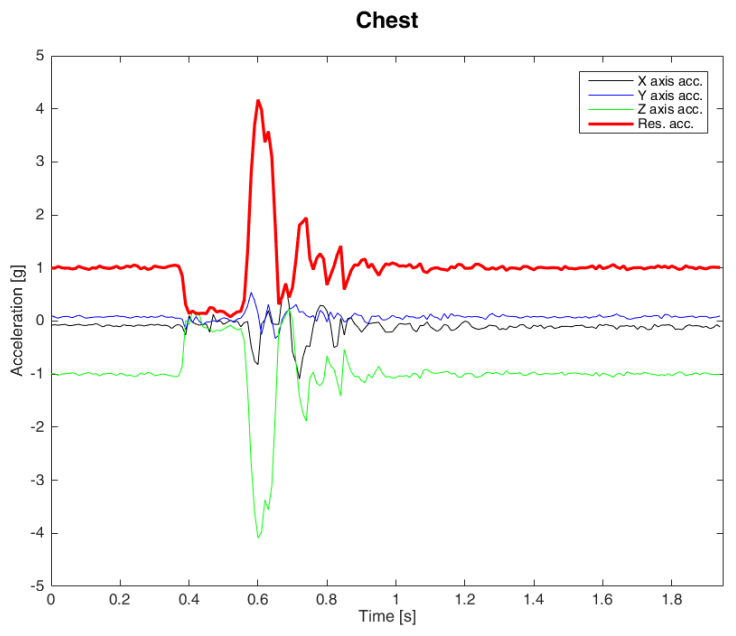

Fig. 11. Profile of registered acceleration values in the dummy chest/neck with the calculated resultant value - TEST 5

in the cabin. The x-direction of acting acceleration causes a bending moment and a tensile force which stretches out hyoid bones in the neck.

\section{ASSESSMENT OF RECORDED RESULTS}

In order to quantitatively and qualitatively analysis of measured accelerations values, the $\mathrm{HIC}$ and Nij indexes were calculated using the equations (1) and (2) for each test (Table 3)

HIC index was calculated for maximum acceleration resultant values recorded in the $15 \mathrm{~ms}$ intervals (assumptive time windows). The components of equation (2) were calculated before

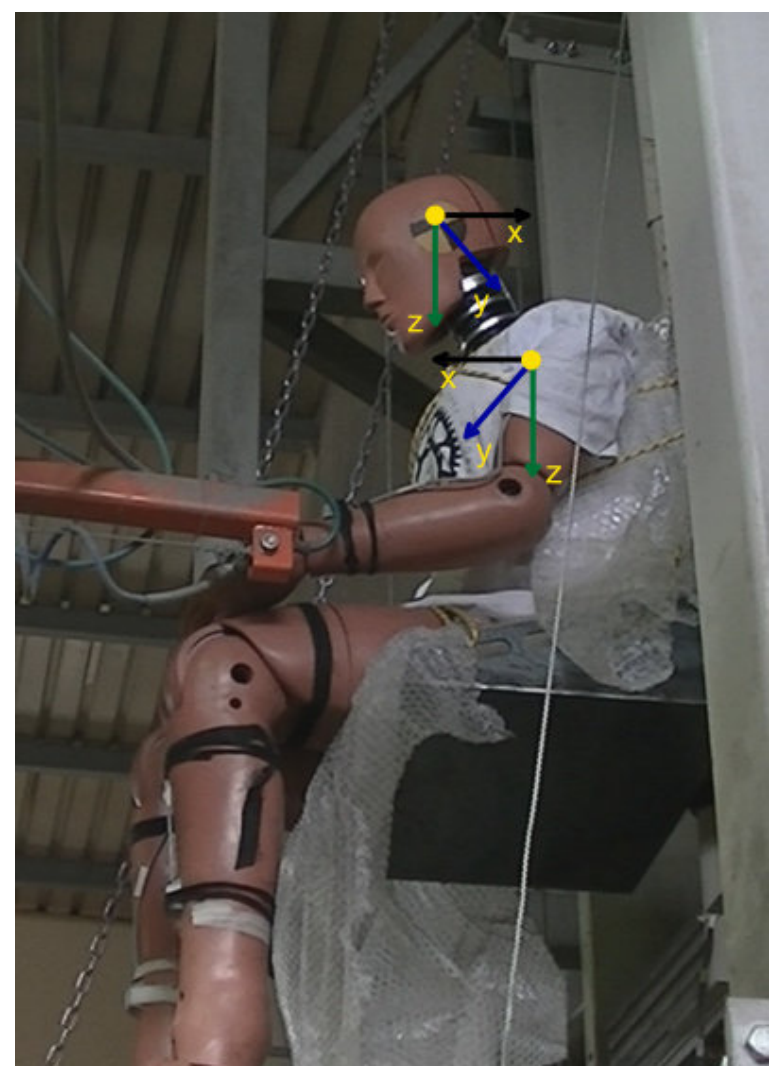

Fig. 12. The dummy with marked axes of head and chest accelerometers

Table 3. Values of HIC and Nij indexes calculated during emergency braking

\begin{tabular}{|c|c|c|}
\hline & HIC $_{15}$ & Nij \\
\hline TEST 1 & 5,05 & 0,22 \\
\hline TEST 2 & 4,75 & 0,28 \\
\hline TEST 3 & 2,80 & 0,36 \\
\hline TEST 4 & 1,74 & 0,36 \\
\hline TEST 5 & 0,71 & 0,35 \\
\hline
\end{tabular}

the value of Nij index. In order to calculate the shearing force acting in the horizontal plane (it is defined by the $\mathrm{X}$ and $\mathrm{Y}$ axes of the mounted sensors), the dummy head mass of $4.54 \mathrm{~kg}$ [15] and the maximum value of the resultant force recorded in the horizontal plane were taken.

The value of the bending moment arm was determined from the base of the cervical segment to the location of the accelerometer in the dummy's head, which allowed the $M_{x}$ to be determined. The critical force values of $F_{\text {xcrit }}$ and $\mathrm{M}_{\text {xcrit. }}$ were adopted on the basis of [17].

The quantitative limit of the HIC index, analysed over $15 \mathrm{~ms}$, is 700 . Above this value may occur a brain injury. Probability of a brain dam- 


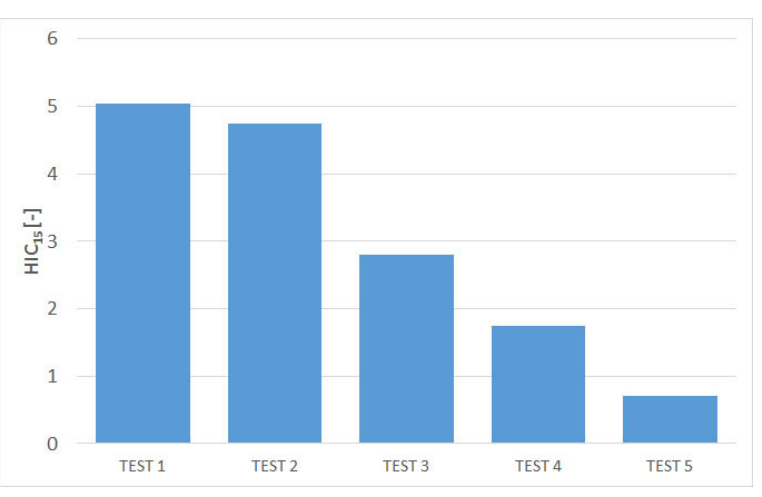

Fig. 13. The values of HIC index obtained during individual emergency braking tests

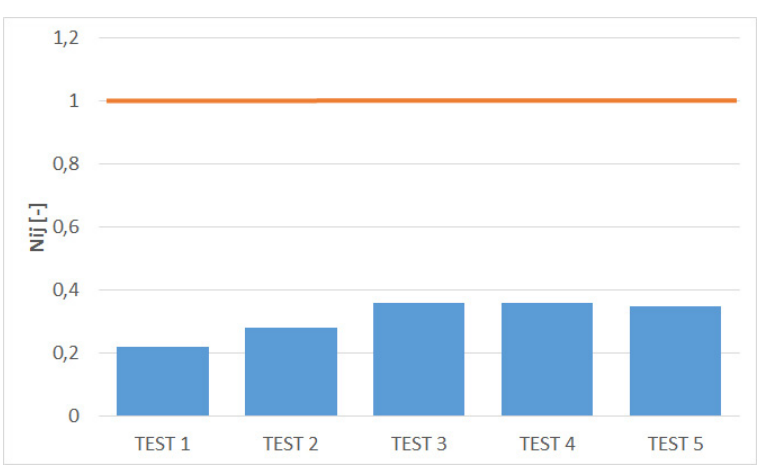

Fig. 14. The values of Nij index obtained during individual emergency braking tests with the limit value marked

age at the level of $5 \%$ is assumed to be $300 \mathrm{HIC}$. Calculated values of HIC index (Figure 13.) for recorded accelerations, during individual emergency braking tests, are negligible relate to the established level of safety.

The calculated Nij values (Figure 14.) for each test did not exceed $40 \%$ of the allowable limit value of the index. It shows no direct danger to the passenger's cervical segment during the emergency braking.

\section{CONCLUSIONS}

The conducted tests of emergency braking of passenger lift cabin shows that installing the progressive safety gears does not adversely affect the health of passengers. Calculated acceleration impact assessment indexes on passenger's heads (HIC) and cervical segments (Nij) did not exceed the limit values. Furthermore, the values of dynamic impacts fall into the accepted standards set in the literature.
Actions leading to providing a shorter braking distance and response time of the safety gear are particularly desirable specifically in passenger lifts, which operating velocities and accelerations due to the high number of floors to be handled, are relatively high. Therefore, carry out the braking tests with recording the dynamic impacts acts on passengers, while increasing the cabin dynamics, is significant in determining an acceptable level of safety.

Additionally, as calculated values of HIC and Nij indexes showed that there is an opportunity to increase the progressive safety gear braking force, as the average deceleration of the whole braking process, do not exceed the gravity of the Earth. However, the dynamic impact on the passengers in short time periods should be checked, when a new construction of safety gears solutions is introducing for providing more efficient braking.

\section{REFERENCES}

1. Directive 2014/33/EU of the European Parliament and of the Council of 26 February 2014 on the harmonisation of the laws of the Member States relating to lifts and safety components for lifts.

2. Eppinger R, Sun E, Bandak F i inni. Development of Improved Injury Criteria for the Assessment of Advanced Automotive Restraint Systems - II, National Highway Traffic Safety Administration, 1999.

3. Funai K, van Schijndel-de Nooij M, van Nunen E. Influence of Elevator Acceleration Induced Loading on Injury Levels, Elevator World, 58 Issue 5, 2010, 86-98.

4. Gadd C. Criteria for injury potential. Impact Acceleration Stress Symposium. National Research Council Pub. Washington, 977, 1961, 141-144.

5. Herrera I, Kaczmarczyk S. The assessment of vibration absorption capacity of elevator's passengers. Journal of Physics: Conference Series, 2009; 181, No.1: 1-8.

6. Herrera I, Su H. Kaczmarczyk S. Investigation into the damping and stiffness characteristics of an elevator car system. Applied Mechanics and Materials, Vol. 24-25, 2010, 77-82.

7. ISO 18738-1:2012 Measurement of ride quality Part 1: Lifts (elevators).

8. Lonkwic P. Influence of friction drive lift gears construction on the length of braking distance. Chinese Journal of Mechanical Engineering, 28, Issue 2, 2015, 363-368.

9. Lonkwic P, Gardyński L. Testing Polymer Rollers Memory in the Context of Passenger Lift Car Comfort, Journal of Vibroengineering, 1, 2014, 225-230. 
10. Lonkwic P, Różyło P, Dębski H. Analysis of the loading impact on the stresses value of the progressive gear body with the use of finite-element method. Eksploatacja i Niezawodnosc - Maintenance and Reliability, 17(4), 2015, 542-548.

11. Lonkwic P, Szydło K, Molski Sz. The impact of progressive gear geometry on the braking distance length under changeable operating conditions. Advances in Science and Technology Research Journal, 1, 2016, 161-167.

12. Lonkwic P., Syta A. Nonlinear analysis of braking delay dynamics for the progressive gears in variable operating conditions. JOURNAL OF VIBROENGINEERING Volume: 18 Issue: 7 Pages: 4401-4408.

13. McCain Z. Elevators $1013^{\text {rd }}$ Edition. Mobile: Elevator World Inc., 2015.

14. Melvin J, Yoganandan N. Accidental Injury: Biomechanics and Prevention. New York: SpringerVerlag New York, 2015.

15. Nahum A, Melvin J. Accidental Injury: Biomechanics and Prevention, New York: SpringerVerlag, 2001.

16. No authors specified. Moderate Overlap Frontal Crashworthiness Evaluation Guidelines for Rating Injury Measures. Insurance Institute for Highway Safety, 2014.

17. No authors specified. User manual of Hybrid III dummy. Humanetics Innovative Solutions, http:// www.humaneticsatd.com/system/files/limited/ UM-H3-50th.pdf (access: 10.09.2016).

18. Ozturk O, Ozbay K, Yang H. Investigating the Impact of Work Zones on Crash Severity by Comparative Analysis. Journal of Transportation Research
Board, TRB's $94^{\text {th }}$ Annual Meeting, Washington, D.C.,2015, 1-18.

19. Petrone N, Ceolin F, Morandin T. Full Scale Impact Testing of Ski Safety Barriers Using an Instrumental Anthropomorphic Dummy. Procedia Engineering, 2, 2010, 2593-2598.

20. Schmit K, Niedrew R, Walz F. Trauma Biomech: Introduction to Accidental Injury, New York: Springer, 2004.

21. Siegmund G, Sanderso D, Inglis J. Gradation of Neck Muscle Responses and Head/Neck Kinematics to Acceleration and Speed Change in Rear-end Collision. Stapp Car Crash Journal, 48, 2004, 419-430.

22. Stemper B, Baisden J, Yoganandan N i inni. Effect of Leading Rate on Injury Patterns During High Rate Vertical Acceleration. Proceedings of the International Research Council on the Biomechanics of Injury, 40, 2012, 217-224.

23. Tyson P. All about G-Forces, What's behind gravity forces, and how much of them can we take?, Posted 11.01.07 NOVA, http://www.pbs.org/wgbh/nova/ space/gravity-forces.html (access: 10.09.2016).

24. Vladic J, Malesev P, Sostakov R, Brkljac N. Dynamic analysis of the load lifting mechanism. Strojniški vestnik - Journal of Mechanical Engineering, 54, 2008, 655-661.

25. Yang S, Tai J, Shao C. Dynamic Partition of Elevator Group Control System with destination floor guidance in up-peak traffic. Journal of Computers, 4, 2009, 45-52.

26. Zhang J, Merkle A, Carneal C i inni. Effects of Torso - Borne Mass and Loading Severity on Early Response of the Lumbar Spine under High-Rate Vertical Loading, IRCOBI Conference IRC 13-19, 2013. 